\title{
Evaluation of the techno-economic viability of Point-to-Point dark fiber access infrastructure in Europe
}

\author{
Marlies Van der Wee, Sofie Verbrugge, Mathieu Tahon, Didier Colle, Mario Pickavet
}

\begin{abstract}
Upgrading telecommunications access networks requires large investments in deploying new optical infrastructure, especially in terms of construction works and costs to reach the end-user, which seem only affordable in densely populated areas. By evaluating a cost-benefit analysis for the deployment of a Point-to-Point dark fiber infrastructure, this paper investigates how the economic risk of dark fiber deployment can be estimated and/or reduced in different settings. By applying the model on specific scenarios, which differ in area type, demand uptake and revenue scheme, it is concluded that the business case is only viable in a dense urban area with an aggressive takeup. In the other scenarios, the paper investigates possibilities and opportunities to improve the business case and hence decrease the investment risk. Examples of this improvement include prolonging the planning horizon, ensuring revenue from the start of the project by performing demand aggregation or examining where public funds might help.
\end{abstract}

Index Terms- Cost-Benefit Analysis, NextGeneration Access Networks, Passive Infrastructure, Techno-Economics

\section{INTRODUCTION}

Following the upgrades of backbone and core networks, the next step in upgrading the telecommunications access networks is deploying fiber all the way to consumers' homes. This upgrade however demands significant investment costs, mostly in the deployment of the passive infrastructure (up to $70 \%$ of deployment cost), and proves to only be viable in densely populated areas [1].

As such, many incumbents defect from investing, not only because of the large investment cost, but also because of regulatory uncertainty. Currently, there is a large number of of laws, guidelines and directives on different levels of the hierarchical decision structure. National Regulatory Authorities (NRAs) should implement the directives formulated by the European Commission, but different opinions and interpretations of those directives often lead to different implementations, which hinder the development of one single telecommunications market across Europe. As exactly achieving this single telecommunications market and offering broadband to all was set out as one of Europe's goals for bringing the benefits of a digital society and economy to Europe's citizens, the business case of deploying Fiber-to-the-Home (FTTH) networks should be explored further by searching for opportunities to improve it [2].

The economic implications of deploying Next Generation Access (NGA) and FTTH networks have been the subject of many studies, papers and publications, all indicating the difficulties and stressing the risks. The literature on the issue is now enormous and only a sample of remarkable work is referred to here ([3] - [8]).

In [3], the authors evaluate the viability of different "flavors" of FTTH, thereby focusing on needed revenues for different market shares and duct availabilities. They define generic areas (clusters), so that each region in Europe can be assumed to be similar to one of them (an approach that is also used in this paper - albeit to on a higher level). They focus on a comparison of different types of architectures (Ethernet Point-to-Point (P2P), Gigabit Passive Optical Network (GPON) over P2P, GPON over Point-to-multipoint (P2MP) and Wavelength Division Multiplexing PON), and provide conclusions on both technological as well as economical results. On a technological level, they conclude that a P2P topology is more future-proof as it can deliver much higher bandwidths whereas for PONs, the bandwidth capacity needs to be shared amongst multiple users. From an economic perspective, their results state that about $64 \%$ of the regions could be profitably covered with GPON, compared to only $50 \%$ with P2P.

A study by Analysys Mason [4] on the UK market furthermore shows the importance of uptake on Return on Investment (ROI). As their study clearly shows that the fixed costs of deployment are much higher than the variable costs, it stresses the need for "demand stimulation initiatives and pre-registration schemes" [4]. This study also applies the clustering method by dividing the United Kingdom into different general 'geotypes'.

In actual FTTH deployments, responsibilities are typically split in three conceptual levels [9]. On the lowest level, the physical infrastructure provider (PIP) is responsible for right-of-way, ducts and fibers. The middle level actor, the network provider (NP), is responsible for the equipment providing network connectivity on top of that (Ethernet and IP layers as well as the wavelength layers if applicable). Finally, there is the service provider (SP) that offers endconsumers the actual services, such as single or multi-play packages, streaming and on-demand services, etc. When zooming in on the cost structure, it is the lowest (physical 
infrastructure) layer that accounts for the largest part of the initial investment cost in network deployment [1], [6], especially when considering buried rollout, which is the most common approach in Europe, and in some regions the only allowed one (as this is a decision taken by the local authorities). Within the total cost for dark fiber rollout (cabling infrastructure), the civil engineering works needed for trenching take up the most significant part of the cost (the manual trenching and installation costs of the fiber are up to 500 times higher than the cost for the actual fibers themselves [7]). It is therefore typically the investment in this layer of the network that is postponed by current telecom operators. Incumbents, for example, focus their strategy on upgrading the existing Digital Subscriber Line (DSL) technology, e.g. through vectoring, instead of deploying new infrastructure [10].

Furthermore, there is a large difference in profitability forecasts for different areas, as can be seen from quantitative analysis of full network deployments (e.g. WDM and TDM PONs - Wavelength and Time Division Multiplexing PONs) in dense urban, urban and suburban areas [3], [4], [8]) as well as from real-life deployments: most operational and successful FTTH networks in Europe are located in larger cities, not in remote areas.

As in a lot of areas, FTTH deployment will not be economically viable, a need rises to search for improvements to the business case of dark fiber deployment, on both technical and economic level. Possible improvements include charging higher monthly prices from end-users, crosssubsidizing from profitable to non-profitable areas or subsidizing from state budget [5]. These proposals are however not certain to work out, as users' willingness to pay will in some cases not exceed the competitive DSL pricing, while state funding is not allowed everywhere by the European Union. One thus has to look for other alternatives, some of which will be presented in this paper.

Within the European project OASE [11], a reference model was developed to calculate costs and needed revenues for the different layers of an FTTH network. This model will be adjusted here to evaluate the business case for passive fiber infrastructure deployment and operations. Based on adoption forecast trends and typical values for population densities, nine scenarios are set up, of which each scenario represents the combination of an identified adoption curve (conservative/likely/aggressive) and an area (dense urban/urban/rural). This systematic approach of defining generic areas and adoption curves allows covering most types of regions in Europe, and is therefore widely applicable as an estimation for the techno-economic viability of FTTH deployment.

This paper will evaluate the business case in each of the proposed scenarios, and will search for necessary improvements in the cases where the results are not economically viable. As such, the effects of social (e.g. demand aggregation) and economic measures (such as prolonging the planning horizon, which is possible for the future proof P2P topology) are combined with earlier proposed technical measures (e.g. duct reuse [3]) as well as political and state intervention (providing subsidies and state aid) where necessary.
Before analyzing the reference scenarios quantitatively, we will first describe the current regulatory policy and funding possibilities in the European Union in section II. Section III will perform the quantitative cost-benefit analysis for the passive infrastructure for the reference scenarios, i.e. under market conditions that can be expected based on current forecast trends. As the results of that section will show, the business case for the PIP will not be economically viable, except for a dense urban area where a high subscription rate can be expected. Section IV will therefore look into possibilities to improve this business case. Section V concludes the paper by indicating economic and policy recommendations to make a viable business case for FTTH access network deployment.

\section{Current Regulatory Regime}

Although the mindset of all regulatory authorities is set in the same direction, namely towards offering broadband to all, and achieving one single telecommunications market across Europe, the variety and diversity of regulatory institutions on regional, national and European level, which all have their own interpretation of the rules and guidelines, make it hard to see the overview. Furthermore, this section will show that public financial aid is not possible in Europe, except for a few specific cases. By presenting an overview of the different regulatory decisions and their consequences, this section gives a further motivation for searching for improvement measures for the business case for the PIP.

\section{A. Current Regulation}

Currently, broadband is regulated in EU Member States by the NRAs in order to avoid distortions of competition and ensure universal access. Incumbent operators, that have a Significant Market Power (SMP), are required to provide access to their networks, in order to enable consumers to choose between broadband providers. The rollout of NGA networks does not remove the existing competition concerns regarding broadband since incumbents could leverage the dominant position they enjoy as owners of non-replicable legacy access infrastructure to monopolize new broadband services provided over this infrastructure and thereby limit consumer choice.

Unless it can be established that NGA access services are markets different from the current regulated wholesale broadband markets, dominant operators with SMP in the NGA markets are comparable to SMP operators on the copper network, and hence, complying with the European Competition Recommendation [12], access to their NGA networks should be regulated.

Taking this into account, the Commission has taken an overwhelmingly favorable view towards State measures for broadband deployment for rural and underserved areas, whilst being more critical for aid measures in areas where a broadband infrastructure already exists and competition takes place.

The Broadband Guidelines [13] outline the rules and conditions on where and how public funding could be provided to build broadband networks in line with the European Union State Aid rules. These Guidelines provide guidance for governments and public authorities on how to finance very high speed, NGA networks, as well as addressing the funding of traditional broadband networks. 
The main aim of the Guidelines is to facilitate a rapid deployment of broadband in Europe by providing to all stakeholders (including local and regional authorities, as well as network operators) a clear, predictable and comprehensive framework for the public financing of such networks. The latter means EU State Aid rules would play a role in channeling public funding to areas where private companies have no commercial incentives to invest - for instance because of the high costs of deploying broadband networks, the low population density or the low levels of economic activities. State Aid can have a crucial role to extend adequate broadband services to all European citizens - no matter whether they are living in large urban areas or in small villages.

\section{B. State Aid and Investment Principles}

In case a Member State supports the roll-out of broadband by way of an equity participation or capital injection into a company that is to carry out the project, it becomes necessary to assess whether this investment will be regarded by the EU as State Aid. In principle, State Aid can play a useful role in cases where the market does not provide sufficient broadband coverage. The concept of "pure" State Aid is defined in Article 87 of the European Community Treaty as "any aid granted by a Member State or through State resources in any form whatsoever which distorts or threatens to distort competition by favoring certain undertakings or the production of certain goods that shall, insofar as it affects trade between Member States, be incompatible with the common market" [14].

In order for a measure to qualify as State Aid, the following cumulative conditions have to be met:

1. The measure has to be granted out of State resources;

2. It has to confer an economic advantage to undertakings;

3. The advantage has to be selective and distort or threaten to distort competition;

4. The measure has to affect intra-Community trade. On the other hand, there are two scenarios in which public investment is not regarded as State Aid in accordance with the Case-law of the European Communities ("ECJ"):

(a) When the capital placed by the State - directly or indirectly- is at the disposal of an undertaking in circumstances which correspond to normal market conditions, it cannot be regarded as State Aid on the basis of the principle of equal treatment within Member States Members. In this case, referred to as the market economy investor principle, the market terms for the public investor should be clearly demonstrated by indicating equal or higher private investment or by a reliable estimate of return-on-investment based on a sound business plan.

(b) When the Member State may consider that the provision of a broadband network should be regarded as a service of general economic interest ("SGEI") [13] as qualified by the Altmark criteria, the State funding may fall outside the scope of State Aid.

\section{Cost BENEFIT MODELING FOR THE PASSIVE INFRASTRUCTURE}

Although deploying an all-fiber network requires more than purely installing the cables in the ground, it is typically the dark fiber infrastructure (also called passive infrastructure) that takes up the largest part of the cost (typically around $70 \%$ ) [1]. Therefore, this section will only focus on the cost benefit analysis for the physical infrastructure provider. Note that all calculations throughout the paper are based on a point-to-point (P2P) access network topology, because this technology allows more flexibility in terms of unbundling and open access (access can be granted at both dark fibre and bitstream layer, while on a point-to-multipoint (P2MP) topology, only bitstream access is technically possible) [15]. Although the paper analyses $\mathrm{P} 2 \mathrm{P}$ infrastructure, it has to be mentioned that the cost of deploying a P2MP network will not differ significantly, as the main part of the cost for physical infrastructure deployment (up to 80\%) is spend on civil works [1], which is similar for both topologies.

\section{A. Scenarios based on area type and expected adoption}

In order to get a good overview of possible outcomes of the business case, nine different scenarios will be studied. These nine scenarios represent a combination of adoption curve and area type. The adoption curves and areas types were not designed to reflect specific areas or situations in dedicated regions in Europe, but aim at providing a range of situations possible to occur (comparable to the approach taken in [3]). Depending on the area and uptake expectations, a different scenario might be chosen to reflect investment decisions.

\section{1) Area types}

Three specific area types are considered: dense urban, urban and rural. They differ in number of households, surface and therefore also cable distance or trenching length (Table I). The parameters were set to optimize the use of cabinets and central offices, and based on discussion with the project partners within OASE.

Table I: Parameters for the area types (note: $\mathrm{HH}=$ households)

\begin{tabular}{|c|c|c|c|}
\hline Area type & $\begin{array}{c}\text { Dense } \\
\text { urban }\end{array}$ & Urban & Rural \\
\hline Number of HH & 15,600 & 8,640 & 3,060 \\
\hline Surface $\left(\mathrm{km}^{2}\right)$ & 5 & 24 & 57 \\
\hline $\begin{array}{c}\text { HH density } \\
\left.\text { (HH/km }{ }^{2}\right)\end{array}$ & 3,120 & 360 & 54 \\
\hline $\begin{array}{c}\text { Fiber length per } \\
\text { HH (m) }\end{array}$ & 831 & 1300 & 2563 \\
\hline $\begin{array}{c}\text { Trenching length } \\
\text { per HH (m) }\end{array}$ & 6.75 & 19 & 46.65 \\
\hline
\end{tabular}

\section{2) Adoption curves}

The outcome of a business model proposal depends heavily on the time-dependent uptake of the product or service by the end-consumers, since exactly these end-consumers have to pay back the investment. In order to reflect this uncertain take-up, we estimated an adoption curve, which is based on the forecasted yearly change in penetration depicted by a discrete form of the Logistic diffusion model [16]. For more details on the model used to determine these curves, we refer to [17].

To model different levels of generic curves, input values for three countries were chosen, because they represent typical 
deployment and uptake status in Europe (Fig. 1). The likely curve represents an average adoption uptake and speed, and is modeled based on the forecast for the Netherlands (where some fiber networks are already present). The aggressive curve models a fast uptake of a large-scale deployment and uptake, as forecasted for Slovakia, while the conservative curve is based on the forecast for Germany, which has a lower speed of adoption than average.

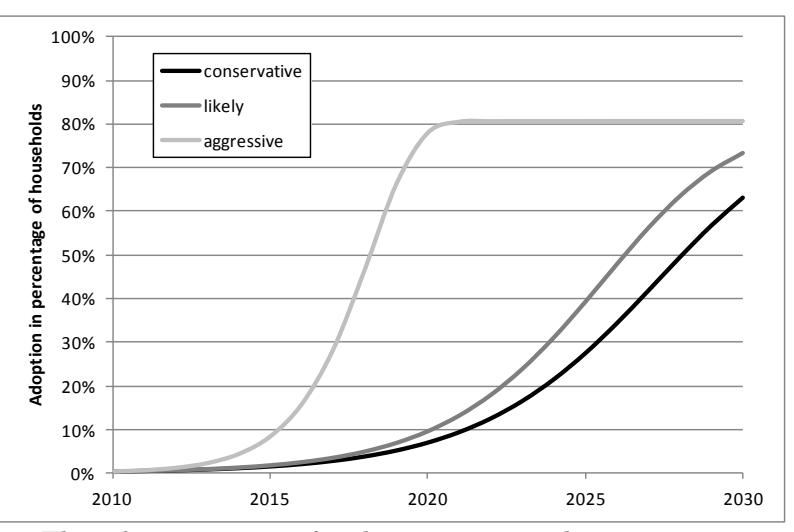

Fig. 1. The adoption curves for the scenario studies

\section{B. Total cost of ownership for a dark fiber network}

Deploying the passive infrastructure requires a huge initial investment that consists of manual labor cost for trenching and costs for fiber cables, ducts and micro-ducts. The combination of this outside plant cost with the upfront cost for installing the necessary, passive, equipment in the central office and street cabinets (e.g. Optical Distribution Frame (ODF) racks), results in the total Capital Expenditure (CapEx) for the PIP (Fig. 2). Note that we only take into account the cost for the access network; our model makes the assumption of not including the in-house cabling and deployment. This cabling can in some cases be taken up by the house owner (in case of single units), or outsourced and paid by the housing organization (in case of multidwelling units), and is therefore not a standard cost for all operators deploying in Europe.

Apart from the upfront investments, there are also costs during the lifetime of the infrastructure: a cable may break, which requires digging and splicing to repair, and renting costs for the floor space in the central office have to be paid every year. These yearly recurring costs are grouped as Operational Expenditures (OpEx).

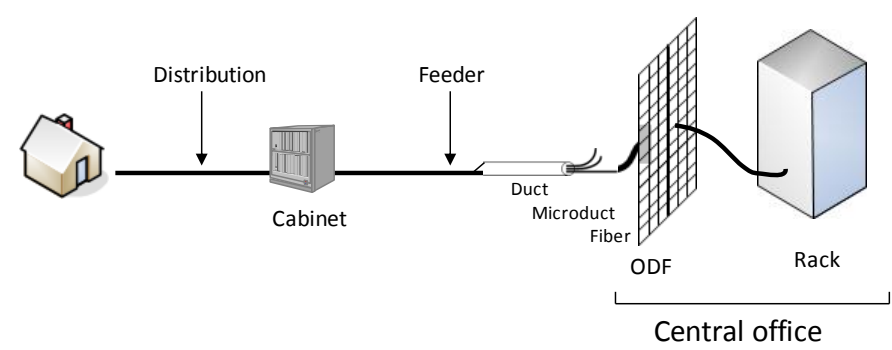

Fig. 2. Overview of the passive infrastructure in a P2P network

The summation of both CapEx and OpEx results in the Total Cost of Ownership (TCO) of the passive infrastructure, and was modeled in more detail in [15]. The main parameters are summarized in Table II and were, similar to the area types, set based on discussions with the
OASE partners. Here, we only show aggregated results on CapEx and OpEx level.

Table II: Unit costs for different parameters, possibly varying over area types

\begin{tabular}{|c|c|c|c|}
\hline Parameter & $\begin{array}{l}\text { Dense } \\
\text { urban }\end{array}$ & Urban & Rural \\
\hline Trenching (per m) & $€ 50$ & $€ 35$ & $€ 20$ \\
\hline $\begin{array}{l}\text { Duct (per m) } \\
\text { depending on diam }\end{array}$ & \multicolumn{3}{|c|}{$€ 3-6$} \\
\hline $\begin{array}{l}\text { Fiber cable (per m) - } \\
\text { depending on number } \\
\text { of fibers per cable }\end{array}$ & \multicolumn{3}{|c|}{$€ 0.3-€ 1.7$} \\
\hline Outdoor Cabinet & \multicolumn{3}{|c|}{$€ 7500$} \\
\hline $\begin{array}{l}\text { Floor space (per } \mathrm{m}^{2} \\
\text { per year) }\end{array}$ & $€ 220$ & $€ 110$ & $€ 170$ \\
\hline Labor cost (per hour) & \multicolumn{3}{|c|}{$€ 45$} \\
\hline
\end{tabular}

The TCO of the physical infrastructure for the three areas clearly reflects the differences in number of users and average distance covered per user (Fig. 3). For the reference scenario, we use a planning horizon of 20 years (based on the trade-off between the lifetime of a passive network and the desired payback period of private investors in the current economic climate), and a discount rate of 5\%, which is based on the reference discount rate for a large infrastructure investments, as set out by the European Union [18], and followed by some countries (e.g. the Netherlands [19]).

Note that a key assumption in our analysis is that the cost of the civil works will not reduce significantly in the long term because it is labor related, while the electronics costs can significantly reduce, according to learning curves' theory [20]. The labor related costs are based on an average of values found for Belgium, the Netherlands, Germany, Sweden Greece and Hungary, for the three types of areas [21].

As the PIP cost is nearly entirely driven by upfront distance-based trenching cost, there is negligible impact from the adoption curves, therefore only the results for the likely curve are shown here. When considering the cost for the physical infrastructure spread over all potential customers $(\operatorname{cost} / \mathrm{HP}=$ cost/ home passed), we clearly see that this is growing with a decreasing household density and therefore increasing trenching cost per household.

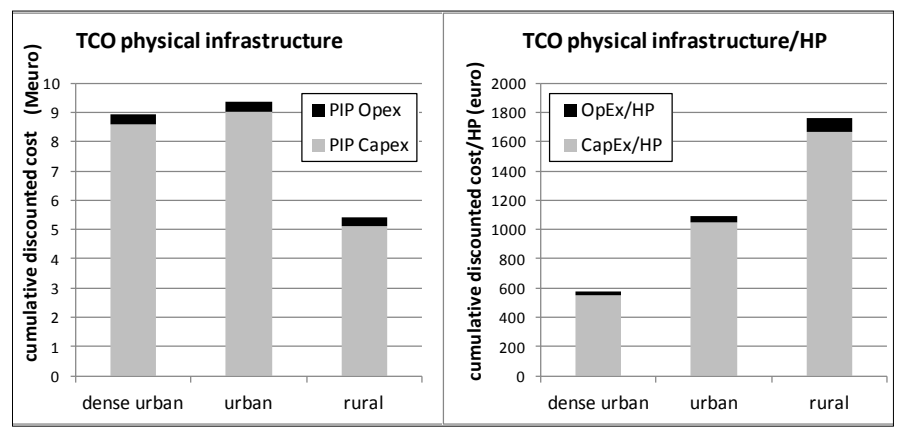

Fig. 3. Total Cost of Ownership for the PIP, cumulative and discounted over 20 years (for likely adoption curve)

Note that the cost/HP in the dense urban area (572 euro) is doubled in the urban area (1094 euro) and tripled in the 
rural area (1764 euro). On the other hand, the TCO for the physical infrastructure also reflects the overall surface and total amount of customers per area. Here we observe that the overall cost for the rural area (5.40 million euro) is significantly smaller than that for the urban area $(9.45$ million euro), which is only based on the significantly lower number of customers. The cost for the dense urban (8.92 million euro) is only slightly smaller than for the urban area.

\section{Expected revenues for a Physical Infrastructure Provider}

Despite massive changes in the telecommunications offer (from voice and analogue TV to Voice over IP, digital TV and fixed and mobile broadband), the total household spend on communications services, as well as the allocation of this amount over the different types of services, remains static over time [22]. Revenue models for funding the physical infrastructure can therefore be based on (i) regulated DSL or fiber unbundling offers, or (ii) on revenues from existing cases.

In the first case, we can expect the PIP revenues to fall in the same range as the current DSL unbundling offers, since new fiber alternatives should be able to compete with existing DSL offers, especially in urban areas. We therefore compare revenues for a FTTH infrastructure provider with the charges OLOs (Other Licensed Operators) currently pay to the incumbent for unbundling of the local loop (LLU) in DSL networks. These regulated prices vary amongst EU Member States, but the average OLO pays between $€ 7$ and $€ 10$ per customer per month for the use of the unbundled DSL local loop [23], [24].

Secondly, there currently exist real-life case studies that apply the open access business model with different actors on different layers. Stokab, the PIP in Stockholm for example, charges $€ 5$ to $€ 7$ per customer per month for dark fiber access in the inner city [25]. Another example can be found in the large-scale deployment of fiber in the Netherlands by Reggefiber, which agreed with OPTA (the Dutch National Regulatory Authority) on prices for ODF access on a regulatory basis, where an operator can choose to apply a region-based tariff or the average national charge of $€ 16.39$ per customer per month [26], [27].

Taking the average of the DSL LLU prices $(€ 7-€ 10)$ and the dark fiber access prices of Stokab (€5 - €7) and Reggefiber ( $€ 16)$, we can assume that a future PIP can expect around $€ 10$ per customer per month. When comparing this value to the basic internet offers of DSL incumbents (in the range of $€ 25$ for use of the infrastructure, equipment and services), assuming $€ 10$ for the use of the infrastructure only seems fair for a competitive provider. As such, this value will be used as an assumption value for the remainder of our calculations in this paper.

D. Cost Benefit Analysis for the nine scenarios under study

Now the costs and revenues for the passive infrastructure have been described and analyzed separately, this section will combine them in investigating the economic viability of the business case for a physical infrastructure provider for the different scenarios described above.

\section{1) PIP business case over 20 years}

With the assumptions at hand, the business case for the PIP over 20 years is only viable in a dense urban area with aggressive adoption (Fig. 4). This means that in all other cases the monthly revenue of 10 euro for the PIP does not suffice to cover for the costs. This observation can be interpreted in two ways. Either the observed time frame of 20 years (or the combination of the time frame of 20 years and the used discount rate of 5\%) is not appropriate for the evaluation of an infrastructure project as considered here; or 20 years is the right timeframe indeed and the business case simply does not fly based on the current regulatory prices. As such, high investments in fiber access infrastructure can be considered unlikely.

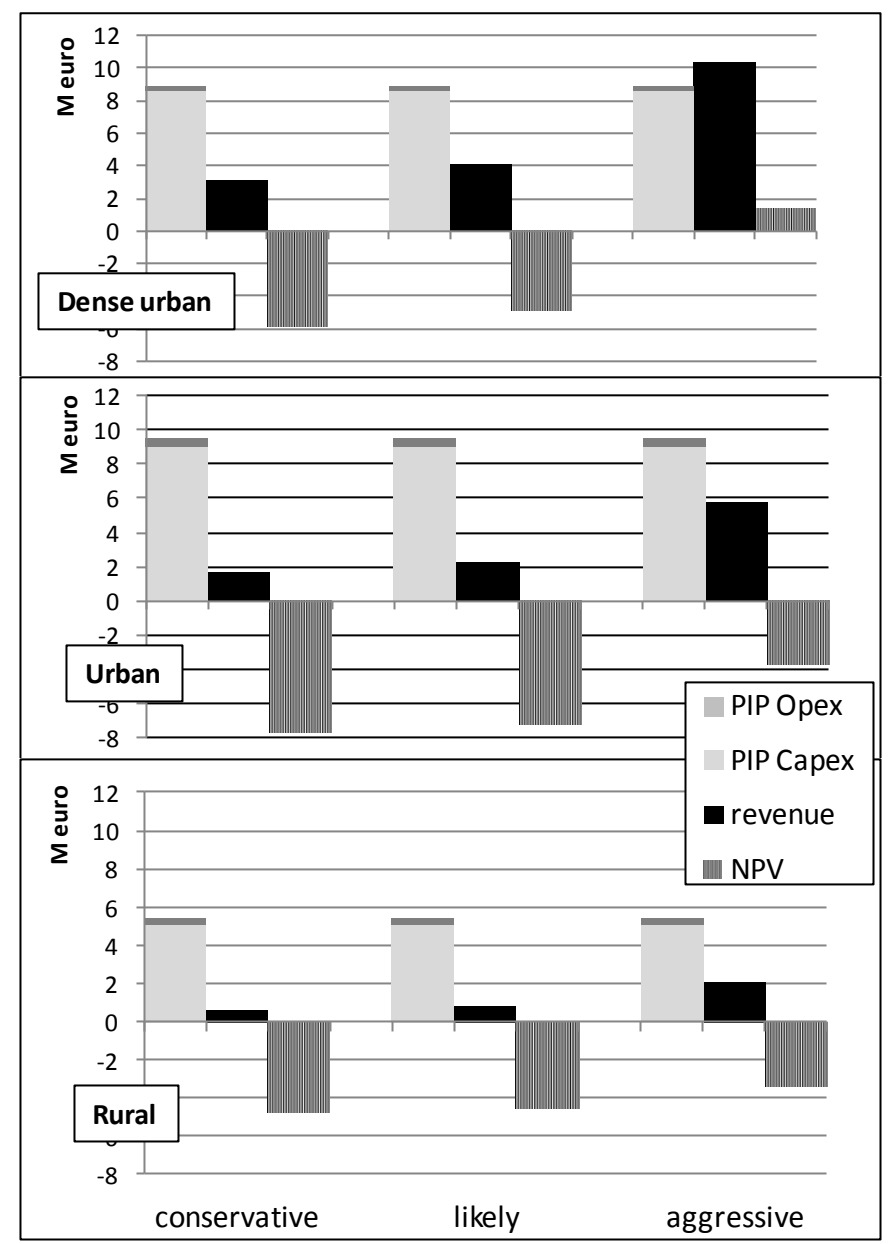

Fig. 4. Cumulative costs, revenues and NPV for the physical infrastructure for the reference scenarios

However, referring back to the real-life deployments operational today (e.g. Reggefiber, Stockholm, etc.), we see that the responsible companies are successful and even expanding their rollouts. Revisiting the parameters used by changing the market, infrastructural and regulatory developments could therefore increase the coverage of viable roll out, but even more subsidies are necessary to make the business case profitable in any area, as will result from the analysis in section IV. 


\section{2) Revenue needed per home connected}

In the previous section, we have calculated the PIP business case starting from known revenues. However, the reverse calculation can give another insight in the problem: we can calculate the revenues needed (per subscriber and per month) based on the known TCO. The following formula is used:

$$
\sum_{i=1}^{20} 12 * X * A(i) * \frac{1}{(1+r)^{i}}=\text { TCO over } 20 \text { years }
$$

where

- $\quad \mathrm{X}=$ revenue per user per month

- $\mathrm{A}(\mathrm{i})=$ absolute adoption in year I, determined according to section III.A.

- $r=$ the discount rate

The formula takes into account a monthly ARPU of $\mathrm{X}$ (multiplied by 12 to arrive at a yearly ARPU), the absolute uptake (adoption) of customers and a discounting factor to incorporate the time value of money. By equating this revenue potential to the above calculated TCO, the needed monthly ARPU can be derived.

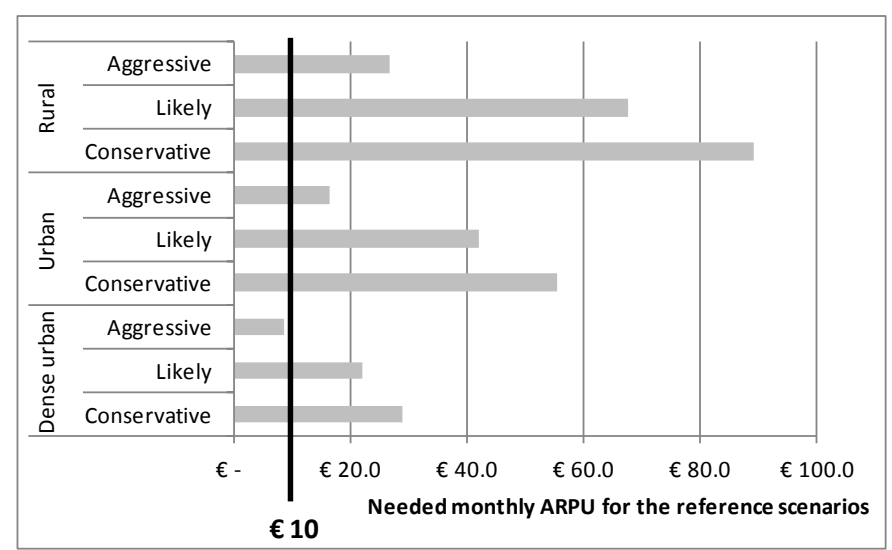

Fig. 5. Revenues needed per subscriber per month for the physical infrastructure for the reference scenarios

The obtained required monthly revenues per home connected for the break even case (Fig. 5) confirm our previous results: only in the dense urban area with the aggressive adoption curve the needed revenue per user and per month (8.6 euro) is lower than the price cap of 10 euro, following the assumptions of section III.C. In all other scenarios, a much higher monthly revenue is needed (for urban at least 16.5 euro, for rural even 26.5 euro, both for the aggressive adoption curve)! Although recently changed and discouraged, these outcomes match nicely with the geographic-dependant price settings used by Reggefiber (see section III.C).

One important remark that should be made at this point, deals with the focus of the model. Although the model was built using a bottom-up approach, thereby ensuring that all relevant parts of the technical calculations are included, the model does not take into account business related and management costs, which are also referred to as transaction costs. In general, a transaction cost is a cost related to an economic exchange, and typically consists out of three parts: search and information costs (related to the amount of standardization of the processes), bargaining costs (negotiations needed in order to settle the contracts) and enforcements costs (required to make sure everything works according to the agreements made) [28]. Although the existence of transaction costs is widely recognized, this paper focuses on the technical production costs and therefore does not take transaction costs into account.

Furthermore, recent literature [29] has shown that in $90 \%$ of investigated large transportation projects, actual costs are higher than estimated costs, on average $27.6 \%$. Since telecommunication access network deployment can be categorized as a large infrastructural project, like roads and railways, it is likely to experience the same effect.

Taking these two reality checks into account when analyzing the results of the business case leads to a risk that obtaining a zero-NPV in an upfront modeling, feeded with realistic data, could still not be economically viable in real-life.

\section{How TO IMPROVE THE BUSINESS CASE?}

Since the results from section III indicate rather negative business cases, while real-life deployments prove the potential economic viability, the model should be adjusted to better reflect improvements measures applied in reality. This section proposes some specific measures that could be taken to make the investment in a passive infrastructure a good choice from an economic point of view. 


\section{A. Impact of demand aggregation}

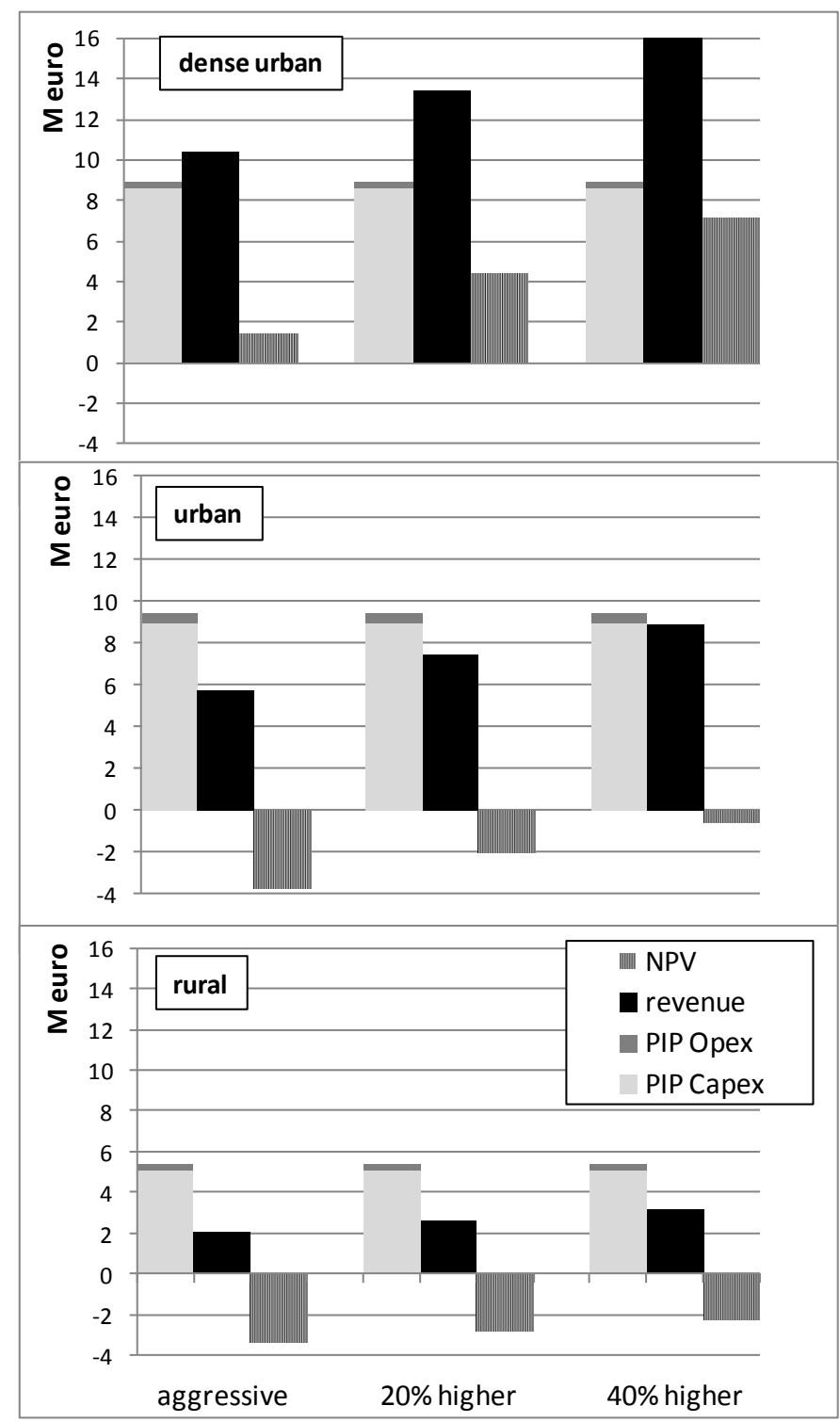

Fig. 6. Cumulative costs, revenues and NPV for demand aggregation of $20 \%$ and $40 \%$ on top of the aggressive adoption curve

The business case for the PIP is especially difficult because of the combination of a high upfront investment with revenues that have a very slow uptake. One solution could be to have high revenues sooner in the project lifetime. Demand aggregation is a process in which interested customers sign a cooperation agreement before the deployment is started. In this way areas can be chosen in which there will be a guaranteed uptake from the start. For example, Reggefiber (the Netherlands) requires, depending on the cost for the envisaged area, a level of $30-40 \%$ demand aggregation before starting the deployment [30].

Based on these realistic assumptions, we have modeled the impact of demand aggregation of 20 or $40 \%$ on the adoption curve, by adding this percentage to the expected adoption. However, we assume that the curve does not exceed the original maximum adoption percentage.

In the dense urban case, the original aggressive curve already led to a positive business case, which is clearly strengthened by an additional demand aggregation. For the urban area, we see that the negative NPV of minus 4 million euro is halved by demand aggregation of $20 \%$ and nearly equaled out by a level of demand aggregation of $40 \%$. The rural case remains difficult though.

Of course, aggregating demand requires extra costs for marketing you offer, and going door-to-door for customer's agreements. This cost however is low compared to the overall gain, and can - to some extent- replace the cost of marketing in a later stage. Another advantage of demand aggregation is the reduction in uncertainty and the cost of estimation.

\section{B. Impact of duct reuse}

It is clear from Fig. 3 that the majority of the PIP costs, and by extension of the entire FTTH deployment cost, is in the CapEx. More specifically it is in the trenching and ducting cost (because we consider only buried deployments), which is significantly higher than the cost for the fiber itself [7]. In case some parts of the ducts can be reused, this will therefore lead to a significant cost benefit. Actual duct reuse can take different forms. Of course, "old" telecom ducts used in the copper network can be an option, but for example in Paris, fiber was deployed in sewer systems [31].

To quantify the effect of possible duct reuse on the business case for the PIP, we compared three scenarios (the percentages differ for the areas under study and are based on discussions with the project partners of OASE [32]):

a greenfield deployment, where no ducts can be reused,

a "small" scenario, where between $25 \%$ and $70 \%$ of the ducts in the feeder fiber section can be re-used, and 15 to $20 \%$ in the distribution cable section of the network (Figure 2),

a "large" scenario, with a duct re-use of 35 to $80 \%$ in the feeder fiber section, and about 20 to $40 \%$ in the distribution cable section.

The variances in duct reuse are explained by a different estimation of the available ducts in the different areas: the available ducts will be much higher in a dense urban region, where most probably, an existing telecom network is already present, while the availability and/or quality of current telecom network is rural areas might be much lower.

Fig. 7 shows the impact of the three levels of duct reuse on the TCO, which clearly is significant. It should be noted that this duct reuse does not always come at zero cost, as owners of the ducts (other operators, utility companies) can charge for their use. In the case an incumbent deploys the fibers in ducts previously used for copper cables, the costs can be assumed negligible (this is the assumption used in this paper, which follows the views by OpenReach, UK, who report a charge per annum of less than $€ 1$ [33]). It should furthermore be noted that, when evaluating P2MP topologies, the duct reuse in the feeder fiber section might be higher, as this topology uses a lower number of feeder fibers than $\mathrm{P} 2 \mathrm{P}$, and as such requires less spare capacity in existing ducts [3].

Because of the higher duct reuse in the dense urban area, the savings that can be achieved are also higher (savings up to $32 \%$ compared to $15 \%$ in the rural area). Reusing ducts makes the business case better, but still not economically viable for deployment in an urban or rural region. 
Total Cost of Ownership for the PIP

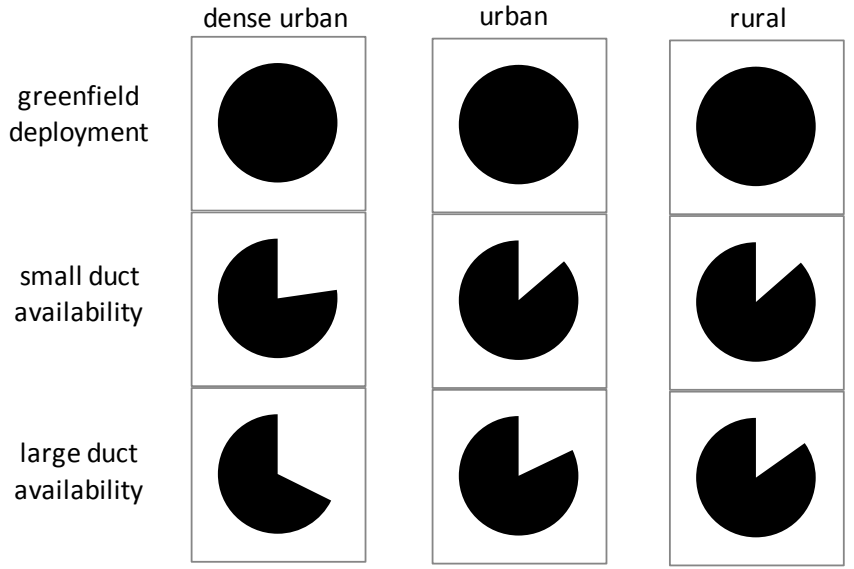

Fig. 7. Impact of small and large reuse of available ducts on the TCO of the PIP

Reusing available ducts is only one option to reduce the overall trenching costs. These costs can also be lowered by using other techniques, like for example, direct buried cable, which installs the cables in a very narrow trench [34]. In the Netherlands, this deployment, immediately in the road, was considered. Aerial deployment using poles or facades is another, cheaper option for deployment [35]. However, in some countries, aerial deployment is not allowed under regional legislation (e.g. major parts of Belgium) or there is, as for example in the Netherlands, "a silent assumption among permitting local governments that new FTTHoutside plant will be trenched" [36].

Finally, the deployment of FTTH can be combined with other utility network rollouts (e.g. water, gas, electricity, etc.), which can entail cost savings of up to $21 \%$ [37]. The disadvantages of this latter approach are clearly the cost of needed coordination: joint rollout requires synchronized planning amongst all utilities, as well as synchronized operations and repair of the cables. Research [38] has furthermore proven that it is not always clear where existing ducts lie exactly, neither is it a foregone conclusion on who owns them. The European Union follows this line of thoughts, as they specify in their guidelines [13]: "Member States may decide in accordance with the EU regulatory framework for electronic communications, for instance, to facilitate the acquisition process of rights of ways, to require that network operators coordinate their civil engineering works and/or that they share part of their infrastructure. In the same vein, Member States may also require that for any new constructions (including new water, energy, transport or sewage networks) and/or buildings a connection suitable for NGA should be in place".

\section{Prolonging the planning horizon}

Since the passive infrastructure that is currently providing internet, the incumbent's copper network or the cable operator's HFC (Hybrid Fiber Cable) network, has been deployed decades ago, and still has not reached the end of its lifetime (if there would be no need for higher speeds, the copper networks could still be used much longer), it is likely to expect that the same holds for the dark fiber cables. It thus makes sense to prolong the planning horizon, since it is very likely that the dark fiber infrastructure will generate revenues for more than 20 years. Furthermore, prolonging the business case will also extend the adoption curve, leading to a higher adoption potential in a later stage of the project (Fig. 1). These revenues are not captured in the initial business case with a lifetime of 20 years.

On the other hand, the current economic investment climate is reluctant towards granting loans for long-term payback periods. The argumentation for the long lifetime of the fiber infrastructure should therefore be assured, as some now do by comparing broadband infrastructure to other network infrastructures, such as electricity or water, roads or railways [19].

When considering discounted cash flows over a period of 40 years (2010-2050, Fig. 8), we observe a discounted payback time of less than 40 years in the dense urban scenario, independent from the adoption curve. Also for an aggressive adoption in the urban scenario, we see a positive case in less than 40 years. The rural case, however, never breaks even within the observed time span.

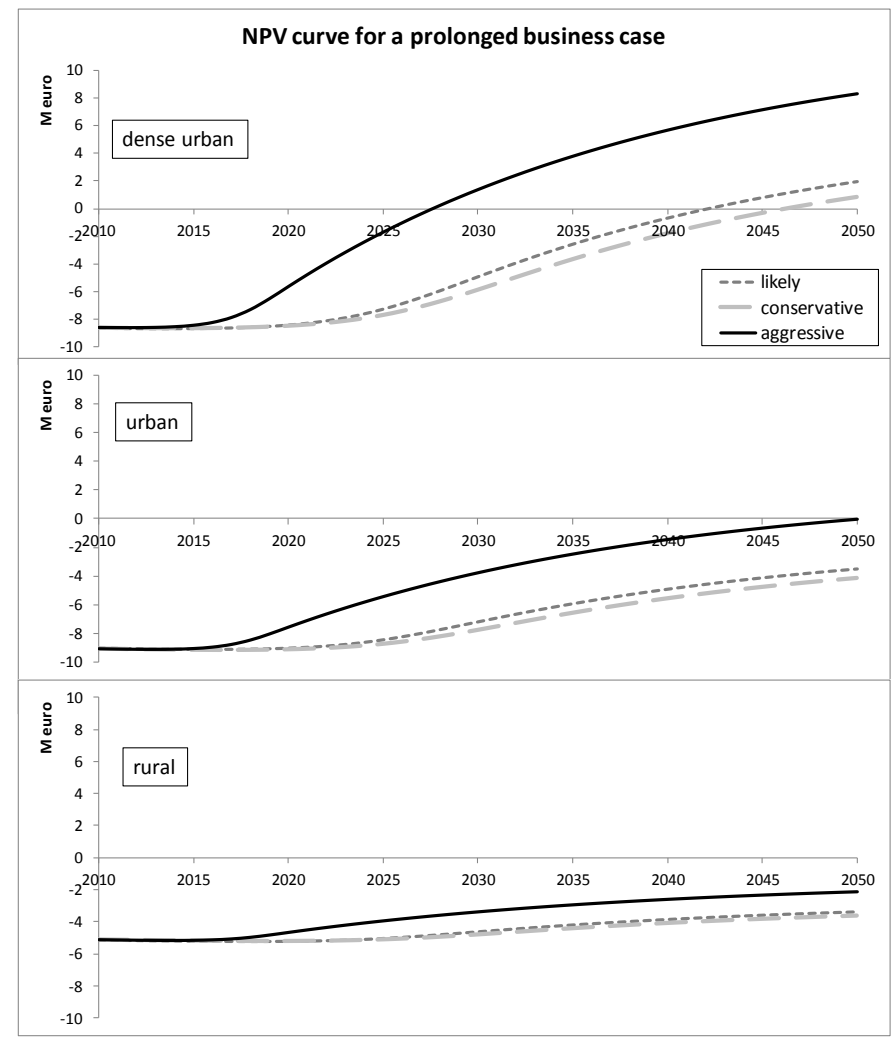

Fig. 8. NPV curves for a prolonged planning horizon of up to 40 years

The difference between the business case for 20 years and 30 years is much higher than going from 30 to 40 years. This can be explained by two effects. First, in 2030, the adoption curve hasn't reached its maximum potential, so more customers will subscribe in 2030-2040 (while the number of new subscribers between 2040 and 2050 is negligible). Secondly, the further in the future the revenues are paid, the higher the effect of discounting, and thus the lower the impact on the cumulative revenue. Therefore, we decided not to look beyond a business case of 40 years.

\section{Additional revenue sources}

Results up till now have assumed PIP revenues based on a per customer fee (of maximum 10 euro), in some cases 
differentiated based on the associated cost (Reggefiber model) combined with an expected adoption for advanced broadband services. However, we can imagine additional revenues for a physical infrastructure provider, as the dark fiber he deploys could also be of interest to non-telco customers. These revenues can be significant, as Stokab reported they can add up to $50 \%$ of their total revenue [39].

Possible additional revenues can come from large businesses or public institutions (like administrations, hospitals, schools, etc.) that want to rent an end-to-end dark fiber connection, and use their own active equipment for lighting it up. This ensures a safe and secure connection between multiple establishments of one enterprise (e.g. a bank). If an FTTH network is present, it can also be used as a backhaul network for Next-Generation wireless offerings, such as Long-Term Evolution (LTE) networks. The base stations of these networks can be connected to the fixed fiber network, and the wireless operators pay their fair part of the lease.

The quantification of these effects however falls outside the scope of this paper.

\section{E. Combining improvements}

Although all separate improvements clearly benefit the economic outcome of the business case, they will most probably not be applied in isolation in real-life cases. Furthermore, the analysis shows scenarios (especially in the urban and rural region) that do not find a positive outcome. It therefore makes sense to combine the improvements to verify whether positive business cases for those areas can be reached.

We chose here to implement a selection of combined scenarios: small or large duct availability, a demand aggregation of 20 or $40 \%$ and a planning horizon of 20 or 40 years. These combined improvements were compared to the reference case (which is the aggressive adoption curve, no duct availability, no demand aggregation and a planning horizon of 20 years). Fig. 9 shows the results for the three regions under study.

Taking into account the assumed ARPU of $€ 10$ per month (red bold vertical lines in Fig. 9 we see that the business case in a dense urban region is actually very positive, with all scenarios remaining well below this threshold. For the urban area, we see that especially the longer planning horizon proves a significant improvement to the business case. The combination of this longer planning horizon with one other measure (at least $20 \%$ demand aggregation or a small duct availability) is sufficient to arrive at an interesting economic case. In the rural area, however, these conclusions do not hold and the business case will never prove to be economically viable. Even when being able to reuse about $50 \%$ of ducts (large availability, which is a rather unlikely scenario due to the low overall availability of "old" infrastructure in rural areas), attracting $40 \%$ of households from the start, and amortize the investment over a time-span of 40 years, the business case still need more than the assumed $€ 10$ monthly ARPU...

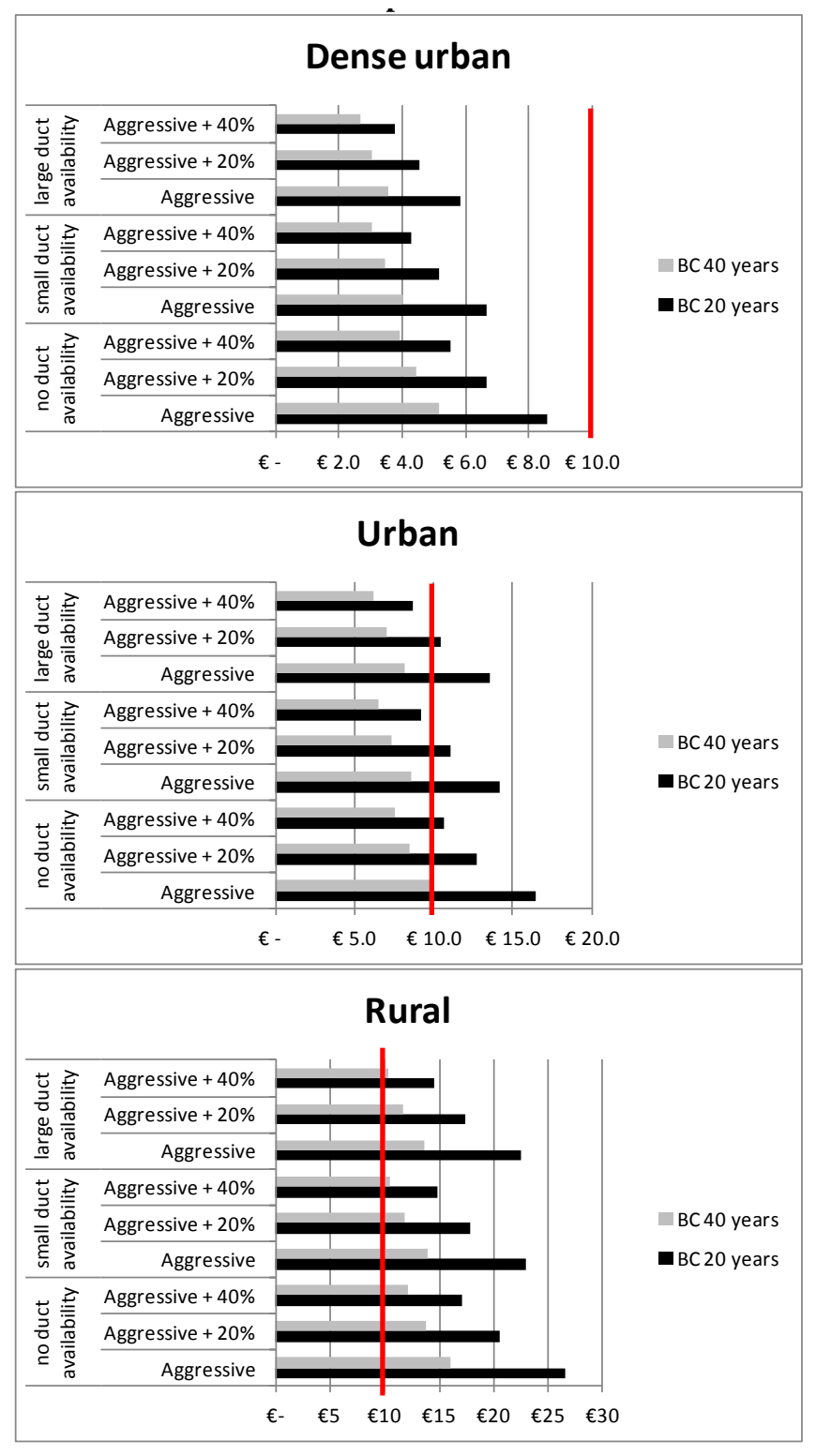

Fig. 9. Needed revenues per home connected for different combinations of combined improvements for the business case for the Physical Infrastructure Provider

\section{F. Use of State Aid or other public funds}

In the previous sections we have indicated that, despite some improvement measures, the business case for the physical infrastructure provider remains very difficult, especially in rural areas. Despite of the potential additional revenues from e.g. non-telco customers, the cost reduction based on duct reuse and the positive impact of demand aggregation on the timing of the revenues, it is clear that there will remain scenarios (combinations of areas and adoption curves) that will not result in a positive business case.

In case the provision of a broadband network is regarded as a service of general economic interest ("SGEI") [13], state funding might fall outside the scope of State Aid and therefore could be a solution to make the case economically viable. Otherwise, in case physical infrastructure is deployed by some undertaking, state funding might still be involved (e.g. in a Public Private Partnership) when the 
capital placed by the State - directly or indirectly- is at the disposal of an undertaking in circumstances which correspond to normal market conditions. A third option allows Member states to call upon the Universal Service Directive to fund underserved regions. This directive specifies that: "Member States must ensure that the electronic communications services detailed in the Directive are made available to all users in their territory, regardless of their geographical location, at a specified quality level and an affordable price" [40]. Finally, when assigning Rightof-Way privileges to operators for densely populated areas, obligations to serve other remote regions can be coupled (cross-subsidizing).

\section{Conclusions}

In its Digital Agenda for Europe, the European Commission stresses the need for high-speed broadband deployment and uptake. Progress in FTTH deployment in Europe however stays limited, as the main argument remains that the initial investment is too high. This paper investigated the business case for the physical infrastructure provider in a buried deployment, as previous research has shown that the civil works needed for deploying this infrastructure take up to $70 \%$ of the total investment. Different scenarios have been calculated, based on reference areas (urban, dense urban and rural), as well as likely, aggressive and conservative adoption curves. Based on an average monthly ARPU of max 10 euro, the case is only profitable in a dense urban area with aggressive adoption. In the other scenarios, the estimated payback time clearly exceeds the considered 20 years, thereby fiercely increasing the investment risk.

It thus makes sense to take a closer look at the business case assumptions, and identify potential refinements that can improve the case and hence reduce the economic risk. Demand aggregation ensures a significant market share and therefore revenue immediately after deployment by having interested customers sign a cooperation agreement upfront. A level of demand aggregation of $40 \%$ can nearly make all scenarios in urban and dense urban areas profitable. Taking advantage of duct reuse has an important impact on the cost base; and leads to significant decreases of the trenching costs. Reusing ducts results in a very positive business case for a dense urban region, and makes the required investment pit for the urban and rural regions less deep, but does not result in a positive business case. Another option is to look for other types of customers than the pure residential ones: additional revenues from public institutions or businesses (both large, medium and small enterprises) can help to improve the case. Furthermore, as we are considering an infrastructure investment here, it might make sense to prolong the planning horizon beyond 20 years. A discounted payback time of less than 40 years was observed in the dense urban scenario, independent from the adoption curve. Also for an aggressive adoption in the urban scenario, we see a positive case in less than 40 years. Since in real-life projects, these proposed improvement measures will not be implemented in isolation, but combined where possible, the paper investigated this impact too. When using more than one improvement measure, the business case for the dense urban area proves to be successful in almost all scenarios; for the urban areas, not all scenarios result in a positive outcome, but successful business cases can definitely be found when directing the market parameters right. We therefore suggest that Member State plans should comprise a balanced set of policy actions to incentivize and supplement private-sector action, with targeted measures for different region types. Private investment should be encouraged by appropriate coordination of planning and rules for sharing physical infrastructure and by targeted financing measures to reduce risk and promote new open infrastructures.

Despite all measures discussed above, even if combined, the business case for the physical infrastructure provider in rural areas seems not to fly. The use of public funds might be the only way out. If the Member State considers the provision of a broadband network should be regarded as a service of general economic interest, state funding might fall outside the scope of State Aid and could therefore be feasible. The same holds when the capital placed by the State is at the disposal of an undertaking in circumstances which correspond to normal market conditions.

The Recommendation on regulated access to Next Generation Access (NGA) networks suggests enabling attractive and fair profits for investors. If implemented, regulated prices for access to fiber networks should therefore fully reflect investment risk for the investing companies. Regulated fiber access prices are only available in a few Member States now (like the Netherlands), however, based on the discussion above we can assume that they will or should on average be clearly higher than the 10 euro assumed throughout this paper. Furthermore, in order to remove risk for the PIP, fiber access prices can reflect costs in some way, e.g. taking into account distances or area types.

\section{ACKNOWLEDGMENT}

The authors of this publication have received funding from the Agency for Innovation by Science and Technology in Flanders (IWT), and this research was partially carried out in the framework of the project OASE. This project has received funding from the European Union's Seventh Framework Programme (FP7/2007-2013) under grant agreement $n^{\circ} 249025$.

\section{REFERENCES}

[1] K. Casier, S. Verbrugge, R. Meersman, D. Colle, M. Pickavet, P. Demeester, "A clear and balanced view on FTTH deployment costs," The journal of the Institute of Telecommunications Professionals, vol. 2(3), pp.27-30, 2008.

[2] European Commission, Commission Communication $\operatorname{COM}(2010) 245$ final/2, A Digital Agenda for Europe. Available:

lex.europa.eu/LexUriServ/LexUriServ.do?uri=COM: http://eur:0245:FIN:EN:PDF.

[3] S. Jay, K.-H. Neumann, et al. "Comparing FTTH Access Networks based on P2P and PMP Fibre Topologies," in Conference of Telecommunication, Media and Internet TechnoEconomics (CTTE), 2011.

[4] Analysys Mason, "The costs of deploying fibre-based nextgeneration broadband infrastructure," report for the Broadband Stakeholder Group, 2008.

[5] S. Jay, K.-H. Neumann, T. Plückebaum, "The Cost of Nationwide Fibre Access in Germany," Communications \& Strategies, No. 85, pp. 169-188, 2012. 
[6] T. Monath, N. Kristian, P. Cadro, D. Katsianis, D. Varoutas, "Economics of fixed broadband access network strategies," Communications Magazine, IEEE vol 41 (9), pp. 132-139, 2003.

[7] N. Ghazisaidi, and M. Maier. "Techno-economic analysis of EPON and WiMAX for future Fiber-Wireless (FiWi) networks," Computer Networks vol 54(15), pp. 2640-2650, 2010.

[8] T. Rokkas, I. Neokosmidis, D. Katsianis, D. Varoutas, "Cost Analysis of WDM and TDM Fiber-to-the-Home (FTTH) Networks: A System-of-Systems Approach.” IEEE Transactions on Systems, Man, and Cybernetics, Part C: Applications and Reviews, vol. 42(6), pp. 1842-1853, 2012.

[9] M. Van der Wee, C. Mattsson, A. Raju, O. Braet, A. Nucciarelli, B. Sadowski, S. Verbrugge and M. Pickavet, "Making a Success of FTTH. Learning from case studies in Europe", Journal of the Institute of Telecommunications Professionals (ITP), vol. 5(4), pp. 22-31, 2011.

[10] Alcatel-Lucent. "Get to fast, faster. Accelerate the existing copper plant with VDSL2 vectoring and bonding," Strategic white paper, Alcatel-Lucent, 2011. Available: www.alcatellucent.com.

[11] OASE, "Integrated OASE Results Overview" White paper. Available: http://www.ict-oase.eu/

[12] European Commission, "Commission Recommendation 2007/879/EC on relevant product and service markets within the electronic communications sector susceptible to ex ante regulation in accordance with Directive 2002/21/EC of the European Parliament and of the Council on a common regulatory framework for electronic communications networks and services" 2007. OJ L344/65. Available: http://eurlex.europa.eu/LexUriServ/LexUriServ.do?uri=OJ:L:2007:344:0 065:0069:en:PDF.

[13] European Commission, "Commission Communication 2013/C 25/01 EU Guidelines for the application of State aid rules in relation to the rapid deployment of broadband networks", 2013. Available: http://eurlex.europa.eu/LexUriServ/LexUriServ.do? uri=OJ:C:2013:025:0001:0026:EN:PDF.

[14] European Commission. DG competition. Article 87 of the EC Treaty. Available: http://ec.europa.eu/competition/legislation/ treaties/ec/art87_en.html

[15] C. Mas Machuca. K. Wang, S. Verbrugge, K. Casier, M. Kind, R. Hülsermann, S. Krauß, "Cost-based assessment of NGOA architectures and its impact in the business model", Conference of Telecommunication, Media and Internet TechnoEconomics (CTTE), Athens, Greece. 2012.

[16] C. Christodoulos, C. Michalakelis, and D. Varoutas, "Forecasting with limited data: Combining ARIMA and diffusion models," Technological Forecasting and Social Change, Vol. 77 (4), pp. 558-565, 2010.

[17] OASE, "Market Demands and Revenues," Project deliverable. Available: http://www.ict-oase.eu/

[18] European Union - Regional Policy, "The Guide to Cost Benefit Analysis of Investment Projects". July, 2008

[19] C. Eijgenraam, C. Koopmans, P. Tang, and A. Verster, "Evaluatie van Infrastruurprojecten. Leidraad voor KostenBatenanalyse." Den Haag: CPB, 2000.

[20] B.T. Olsen, and K. Stordahl, "Models for forecasting cost evolution of components and technologies," Telektronikk, 4, pp. 138-144, 2004.

[21] Eurostat, "Labour costs in the EU27", Eurostat news release, April 2013. Available: http://epp.eurostat.ec.europa.eu/cache/ ITY_PUBLIC/3-10042013-AP/EN/3-10042013-AP-EN.PDF.

[22] OfCom, "Communications Market Report," 4 August 2011. Available: http://stakeholders.ofcom.org.uk/binaries/research/ cmr/cmr11/UK_CMR_2011_FINAL.pdf

[23] Bundesnetzagentur, "Pressemitteillung: Bundesnetzagentur gibt endgültige Genehmigung der Entgelte für die „letzte Meile“ bekannt." 17/06/2011

[24] OPTA, "Besluit Wholesale Price Cap 2009-2011 (WPC-IIa besluit)," OPTA/AM/2009/203507, December 16, 2009.
[25] A. Broberg, "Stockhom IT-infrastructure", Workshop presentation. Stokab, Stockholm, February 2011.

[26] Telecompaper, "Reggefiber, KPN to adjust wholesale tariffs," (31/12/2012). Available: http://www.telecompaper.com/news/ reggefiber-kpn-wholesale-to-adjust-fibre-tariffs--916449.

[27] Reggefiber, "Annex: Tarieven bij Overeenkomst inzakegebruik van passieve glasvezel-aansluitnetwerken." Version 2.4. Available: http://www.eindelijkglasvezel.nl/tl_files/documents/ Generiek\%20ODF\%20contract/Annex\%20Tarieven\%20bij\%20 ODF\%20overeenkomst\%20Reggefiber\%20v2\%204.pdf.

[28] O.Williamson, "The economics of organization: The transaction cost approach," American journal of sociology, vol. 87(3), pp. 548-577, 1981.

[29] B. Flyvbjerg, M. Holm, S. Buhl, "Underestimating Costs in Public Works Projects: Error or Lie?" Journal of the American Planning Association, vol. 68(3), pp. 279-295, 2002.

[30] W. Burger, "The Reggefiber model. Key elements of Reggefiber's strategy in the Netherlands," 2012.

[31] H. Väätämöinen, "What Solution Providers need to know about FTTH?" Presentation of Draka at the 5th BICSI Southeast Asia Conference, 2007.

[32] OASE, "Process modeling and first version of TCO evaluation tool". Project deliverable. Available: http://www.ict-oase.eu/.

[33] OpenReach, "Physical infrastructure pricing," Available: www. openreach.co.uk/orpg/home/products/pricing/loadPricing.do

[34] FTTH Council Europe, "FTTH Handbook," 2012.

[35] FTTH Council Europe, "FTTH Infrastructure Components and Deployment Methods". Issued for Barcelona 2007.

[36] H. Rood, "Very high speed broadband deployment in Europe: the Netherlands and Bulgaria compared", TPRC, 2010.

[37] M. Tahon, J. Van Ooteghem, K. Casier, S. Verbrugge, D. Colle, M. Pickavet, and P. Demeester, "Improving the FTTH business case - a joint telco-utility network rollout model," Telecommunications Policy, in press, 2013.

[38] European Commission, "Impact Assessment Accompanying the document: Proposal for a Regulation of the European Parliament and the Council on measures to reduce the cost of deploying high-speed electronic communications networks." SWD (2013) 73 final. March, 2013.

[39] A. Broberg, "Challenges for an open physical infrastructure provider," Workshop presentation at the ECOC conference, Amsterdam, the Netherlands, September 2012.

[40] Europa.eu, "Universal services and users' rights." Available: http://europa.eu/legislation_summaries/information_society/leg islative_framework/124108h_en.htm 